\title{
OTRA DEDUCCIÓN DE LOS PRINCIPIOS DE LA FILOSOFÍA POSITIVA
}

\author{
Friedrich W. J. Schelling
}

Recibido: 23-11-2017

Aceptado: 17-07-2018

Nuestro punto de partida es lo que antecede al pensamiento, el existente incondicional. La tarea con respecto a lo que se nos da de antemano; es decir, el ser o el existir incondicional (pues en realidad es lo único que vemos al comienzo, mientras el qué (Was) nos queda aún oculto) es hallar la verdadera Monas (die Monas); es decir, lo que permanece, encontrar el principio que está por encima de todo. Así, la pregunta es precisamente si todo el pensamiento del ser precedente; esto es, la Monas, que queremos denominar el ser imprepensable, puede estar localizado en este ser imprepensable. Quizá este ser es sin duda sólo el primer ser, el primer modo de aparición de la verdadera Monas. La pregunta entonces es si aquel ser imprepensable admite alguna oposición por la que quede alterado, y por la cual pudiera comportarse como lo contingente. Nosotros debemos partir de él, liberarnos del ser imprepensable para acceder a la Idea. Esto sería únicamente posible si aquel ser imprepensable fuera mostrado de nuevo como lo contingente a través de la dialéctica. No como lo contingente por antonomasia, sino como lo contingente que es lo necesario. Hemos señalado ahora que en el existente imprepensable ganamos el Actus de toda Potencia. El existente necesario no es posible y entonces por ello efectivo, sino que es efectivo ya, él comienza directamente con el ser. Así pues, aquel qué (Was) aún desconocido, aquella $x$ del ser imprepensable es libremente antecedenter o a priori sólo el ente (das Seyende). Pero nada impide que incluso el ente a priori sea el ente a la mano, el poder-ser post actum (como realmente decimos aquí con razón). Decimos que nada lo impide, pero tampoco decimos todavía que sea efectivamente así. Esto deberá demostrarse por tanto mediante una consecuencia a posteriori. La posibilidad sólo se comprende a priori cuando el modo precedente del ente puro sea el poder-ser a la mano. Precisamente por eso, porque no ha salido en primer lugar la potencia del ser imprepensable, no podría tampoco este existir imprepensable ser superado en el Actus. Queda así establecido justamente en este existir imprepensable una contingencia no excluyente. Lo que una posible contraposición puede anticipar tiene tan sólo frente a dicha contraposición un ser contingente en la medida en que permanece posible. Supongamos que yo eligiese entre ta y -a y me hubiera decidido por $+\mathrm{a}$, de modo que -a quedase siempre excluido. El ser ta no es nada falso 
(blind) siempre y cuando sea pensado con necesidad otro contingente, que por otra parte tampoco es contingente porque se trata de un ser puesto por la voluntad. Pongo incluso tan sólo $+a$, sin elección, de modo que -a es anterior, pero sin quedar excluido para siempre. $\mathrm{O}$ mejor dicho no es excluido en general, permanece todavía como posibilidad, de modo que se ofrece a la mano y reclama su validez. Así pues, es algo contingente justo en el actus puro como tal. El mero existente necesario actu, algo semejante a lo que tenemos hasta ahora, es el mero existente contingente necesario o, como puede ser también llamado, el existente ciego. El existente ciego es el mero existente contingente necesario, el cual excluye por ello el poder-ser sólo como antecedens, pero no de un modo absoluto. El poder-ser simplemente, y como tal, no tenía ningún derecho a existir. Después empero de que el mero actu sea; es decir, el mero necesario contingente, la mera posibilidad puede también alzar su exigencia. El ser imprepensable hace así aparecer ya como posible a la potencia. Justo en este punto se clarifica que el poder-ser precedente no pueda carecer tampoco de una relación sobre el mero ente. Por tanto, y no otra cosa sino sólo lo que se presenta como el mero existente mismo, puede también ser la potentia existendi que se contrapone a aquella. La potencia no puede aparecer bajo la presuposición del ser, de modo que debe haber entre ambos una unidad; es decir, debe ser tanto el mero existente como la potentia existendi. Pero mientras pongo esto de manifiesto, también digo que el mero ente infinito es a su vez la infinita potentia existendi o el poder-ser infinito. Queda ya establecido aquello que es más que el mero Existente, lo que trasciende el mero actus del existir, lo que puede estar por encima de éste, y lo que precisamente por ello no puede ser más el mero actu necesario existente. Únicamente el existente fundamental; es decir, el existente necesario, puede ser ahora la natura necessaria, que es también independiente del existir efectivo, del actus del existir. El existente necesario es, de un modo señalado, conforme a su naturaleza o a su esencia.

Esta natura necessaria sería también inicialmente y antes de nada: 1) el ente imprepensable, 2) lo otro que se encuentra en la posición de poder ser, 3) lo libre entre ambos como espíritu que planea desenvueltamente, pues ellos se comportarían frente al poder como ser, y frente al ser como poder. Así el ser imprepensable se hace libre frente al poder, y el poder libre a su vez frente al ser imprepensable, de forma que la natura necessaria puede ser y no ser ambas cosas, tanto el ente (Seyende) puro como aquello que el ser imprepensable podía ser mediante el poder-ser. La natura necessaria, como unidad indisoluble de estos tres momentos, sería también la absoluta esencia libre que es libre de un modo señalado 1) en la visión del ser que se le muestra, siendo lo otro de su ser originario (su ser imprepensable). La natura necessaria es libre 1) en la visión de este otro

Thémata. Revista de Filosofía №58 (2018) pp.: 35-48. 
ser. Ser libre significa $a$ ) no poder querer la misma cosa: es así también lo independiente de este ser y Es (existe) por anticipado para él. Este ser es cierto a priori. Por ello es justo lo libre, que quiere decir $b$ ) querer este ser, mientras lo posee en el actus del existir imprepensable, por el cual puede ser también de nuevo aquel otro ser igual de poderoso que su Señor. Pues este actus sería por mor de la aparición del otro ser, quien le arrebataría su posición, cobrándose el espacio al ser. Como actus no quedaría sin embargo anulado en su raíz. Sólo en la potencia del actus infinito llegaría a ser potencia, que en cambio estaría anulada con el poder irresistible del actus reestablecido a través de la superación; es decir, a través de la continuada potencialización de aquel ser salido de la potencia, que ahora se le opone y le desplaza igualmente del lugar del ser. Sería sin embargo tan libre como la natura necessaria frente al poder-ser, estaría 2) también frente al ser imprepensable mismo. La natura necessaria no está constreñida por tanto a perseverar en el poder-ser, sino que puede aparecer fuera de él. Este ser imprepensable mismo realiza nuevamente durante un momento su movimiento, su propia vida. Pues incluso así, cuando la vida anula también este ser imprepensable para el actus, la naturaleza necesaria permanece como necesidad. Aunque ella es el poder-ser, sin embargo, tiene de antemano el ser, siendo con ello ahora libremente el verdadero poder-ser. El verdadero poder-ser es aquello cuyo ser, como ser frente a toda posibilidad precedente, es independiente, seguro, y por ello cierto, y a través del que ningún ser subsiguiente puede llegar a ser superado. Dado que asegura este ser infinito, se le ve indistintamente asumir o no asumir su posición en la libertad del otro ser. Pues en esta misma situación, lo que permanece independiente del existir efectivo del existente es, por tanto, el supraexistente (bajo el que se entenderá justamente lo que es también independiente del Actus del existir del existente). Así, ello es enteramente indiferente (perinde est) tanto si adopta este otro ser como si no lo adopta, y lo realiza a través de la nuda voluntad de la posición del ser, poniéndose de esta manera el ser imprepensable en tensión y negación. O también si se retira inmediatamente de nuevo aquel mero ser imprepensable como el posible indicado ser en la potencia, o, más bien, si es dejado en la posibilidad desnuda. Así pues, esta posibilidad no es nada si ella no lo quiere en el imprepensable ser del ente. Esta posibilidad es algo sólo cuando ella lo quiere. Cuando por ello esta posibilidad alcanza el ser correspondiente, queda simplemente afirmada como tal esta posibilidad y únicamente a través de su solo ser; o sea, a través de su voluntad divina. (Conocida como tal posibilidad, aceptará el fundamento de toda creación de lo que en general no niega la creación como tal, y como no deja de ser señalado por los teólogos, con una materia [la mera materia todavía sin forma] creada a través de la mera voluntad divina de un modo libre, condición sin cuya

Thémata. Revista de Filosofía Nº58 (2018) pp.: 35-48. 
aceptación no puede ligar ningún otro concepto comprensible). La posibilidad de otro ser aparece incluido en el ser originario - el ser marcha delante, la posibilidad no llega sino después del ser, pero ésta aparece para él a partir de entonces en el imprepensable ser del ente, por tanto en la eternidad. Aquí yace la explicación de esta habitual expresión. Eterno es aquello a lo que ni tan siquiera el pensamiento mismo puede anticiparse una sola vez. He escuchado a menudo objetar contra este ser al que llegamos tan de repente, que la entera posibilidad de tal efectividad anticipada no pueda ser pensada. No estamos acostumbrados evidentemente a un pensamiento que anteceda al ser. El pensamiento pone justo este ser como su punto de partida, el cual le resulta lo más sugerente, también por tanto como lo más deseable para el saber, y con el que acceder a partir de éste a una realidad efectiva. El pensamiento efectivo está en el punto de salida de esta posición, como el terminus a quo de un movimiento en el que dicho movimiento en realidad tampoco es tal movimiento, y sin embargo, forma parte también del movimiento. De este modo aquel ser devendrá como tal en el desarrollo, en el hacer pasar a este movimiento mismo con un momento del pensamiento. Aquella objeción debería sin embargo significar lo siguiente: que tampoco pudiera presentarse tal posibilidad anticipada de una realidad efectiva ni tan siquiera una sola vez. Este punto queda así también rechazado. Por tanto, tal ser debe presentarse en ciertas ocasiones, por ejemplo en el caso de producciones, hechos o actuaciones cuya posibilidad está dada a través de su realidad conceptual efectiva. Lo que se plantea para un concepto existente previo a todo nadie puede llamarlo original. Original es donde se reconoce ya la posibilidad, cuando se ve la realidad efectiva delante de los ojos.

Eterno es el ser que está en Dios, antes incluso de que Él mismo pueda pensarlo. Dios mismo alcanza primeramente a ser su eternidad en su salida de sí al exterior. La eternidad, junto con el resto de atributos que le pertenecen conjuntamente a Dios, han sido denominados negativos por parte de las especulaciones de los teólogos. Examinadas suficientemente estas especulaciones, se muestra que son constantes aquellas que tratan de ser pensadas junto y ante Dios; es decir, frente a su divinidad, y sin (ohne) las que, en cambio, Dios no puede ser, pero con las que Dios tampoco se muestra como lo que es. Pues por ejemplo también la substancia espinosista es eterna, sin presuposición alguna, sin ninguna razón eterna, y efectivamente ella no es Dios. Dios no podría de otra manera ser Dios si no fuera eterno. La eternidad es una conditio sine qua non de su divinidad. Una eternidad sin fundamento, de la que efectivamente no hay ninguna ciencia, ningún pensamiento, pues aquélla, como dice Kant con razón, es el abismo de la razón. Esta eternidad es justo por ello sólo un momento, sólo un punto de partida, del que hemos salido inmediatamente, y que sólo pone

Thémata. Revista de Filosofía ํ58 (2018) pp.: 35-48. 
la ciencia para poder salir de dicho punto. A tal terminus a quo devendrá esta eternidad consecuentemente en el momento en que pueda hablarse de la eternidad. En la eternidad misma no está por lo tanto aquel ser sin fundamento. Pero el fundamento está sólo puesto con la finalidad de salir de él. De ahí en adelante, se muestra la eternidad como lo eterno mismo como posibilidad de otro ser que está justamente desgajado de su eternidad ciega, eternidad del mero existir para llegar a la eternidad de la esencia, a la eternidad de la Idea. Esta posibilidad resulta incluso, de cara a la Idea, como algo que no se ha dado anteriormente, algo inopinado. Pero aunque algo imprevisto no es para él un invisum, algo no bien recibido, en otro sentido es también algo bien recibido. Pues mientras ella le muestra un ser que puede elevar a la realidad efectiva a través de su mera voluntad, le da algo en general que puede querer - algo en general que poder estar queriendo y que anteriormente no tenía; es decir, un mero ser - y un poder para el no-ser. Mientras aparece esta posibilidad se eleva el mero ser imprepensable hacia aquello que va más allá aún de éste; es decir, es también el poder-ser, Señor de un ser que todavía no es. De este modo es a la par libre de constituirse en el ser imprepensable, del que no era Señor, no siendo por tanto ser de sí mismo, pero llega a ser igualmente ideal - al menos por lo que hace a su presentación - por medio de la aparición de aquella potencia que está completamente despegada en la voluntad del ser imprepensable. La aparición de aquella posibilidad original ofrece, por tanto, lo que en el ser imprepensable es ya en sí mismo el auténtico ente (Seyende). Justo en este ser, que se le muestra como posible, anhela por tanto, al mismo tiempo, liberar el medio, que también es real con respecto al ser imprepensable. Así como tenemos al Señor como opuesto al ser imprepensable, se le ve al mismo tiempo como Señor de este ser impreprensable, todo ello del siguiente modo: piénsese el Señor de un ente que no es todavía, de un ente que es sólo posible, y que se revela como un ser contingente cuando al fin es. Piénsese así este ser contingente como surgiendo, de manera que se dará de bruces con lo que no puede surgir, aquello que no tiene precedentes, se dará con el ser originario. Este ser originario aparece también ahora como lo eterno. Pero más aún: este ser contingente no puede surgir por sí sólo, y en cambio surge ahí donde anteriormente no había nada como lo eterno, nada como el ser necesario. Por tanto, no puede surgir sin trascender a éste. Llamamos $A$ al ser eterno, de modo que $B$ será lo contingente, lo ya surgido, lo totalmente desigual a $A$. Donde por tanto no era de un modo imprepensable como el puro $A$, se presenta ahora $B$, lo que trasciende a $A$ de un modo excluyente. Éste, que hemos conocido como puro actus, como puro punto de partida, en modo alguno negado o inhibido por nada, como tampoco reflexionado por nada o vuelto a brotar de nuevo en sí mismo, tiene ahora lo opuesto. De esta forma viene a estar trabado por medio de ese

Thémata. Revista de Filosofía Nº58 (2018) pp.: 35-48. 
nuevo ser recién surgido que se ha movido hasta lo más elevado. Algo así a como cuando una parte de un organismo viviente previamente en reposo deviene activa, encendiéndose desde su pasividad (la activación no tiene nada que ver con un devenir activo procedente de la potencia aparecida). Así como la parte despierta se alza sobre la parte dormida, ésta no permanece eodem loco, quo fuerunt, y el ser recién surgido continúa actuando sobre el ser que previamente había hecho acto de presencia. En este ser antes inamovible llega por tanto una movilidad previa. Este ser llega a ser él mismo también otro, recibe una negación en sí, recibe una potencia, y estará él mismo puesto de esta manera para un ente (Seyenden) (ahí donde estaba el ente (Seyende) originariamente inicial). En efecto, pone así verdaderamente atención a la esencia para no ser según el actus purus. Pero éste no es más actu, sino sólo todavía algo conforme a la esencia. Ahí la esencia es igual a la potencia, es por tanto la potencia infinita del actus purus, el cual se impone por su naturaleza como tal actus purus. No es ya más la potencia pura, desinteresada, no reconocida en sí misma. $\mathrm{Ni}$ tampoco es lo sabio en sí mismo, como lo era antes. Y en tanto que recibe en sí una negación; es decir, una potencia, ha devenido un ente (seyendes) para sí. Anteriormente era ante sí camino, puro salir de sí. Ahora es en sí mismo lo retornante, lo devenido potencia para sí mismo; es decir, lo que se ha convertido en ente (seyenden) para sí. De este modo vemos como él, a quien hemos visto ya como Señor de lo contingente, del mero ser posible, en tanto que es el Señor, puede sentar o no este ser contingente. Así como él ha llegado a afirmar también su ser originario como Señor, que Él puede sentar ex acto puro in potentiam a través de la aceptación del ser que se le muestra desde el ser puro en un ente, y alcanzar así a metamorfosear su existir necesario mismo en algo contingente (lo contingente bajo esta forma negada). Él puede anular este ser originario, porque permanece sin embargo independiente de él; es decir, sin ser actu del existente. Pero su naturaleza permanece conforme al existente necesario, según la natura necessaria.

Este sería por tanto el modo como la filosofía positiva puede comenzar por sí sola por el ente imprepensable, con el que, con todo rigor, no ha comenzado todavía nada. Intentaré presentar ahora el paso de este desarrollo de nuevo, pero de un modo distinto. Y es que no nos encontramos aquí en el área de lo necesario, sino en el de lo libre; es decir, del auténtico pensar especulativo. La expresión especulación debería estar reservada para la filosofía positiva, como por ejemplo la mathesis elemental no puede tampoco ser llamada especulativa: lo más elevado es únicamente la mathesis especulativa. Especular quiere decir mirar atrás en torno al conjunto de las posibilidades, a través de las cuales poder llegar a alcanzar un fin cierto para la ciencia. Estas posibilidades son naturalmente sólo 
posibilidades inmediatas que, confirmado el éxito, deben revelarse como auténticas realidades efectivas, así como en las conclusiones hipotéticas puestas en la premisa mayor (Obersatz) como hipótesis, en la oración de conclusión quedan como una verdad demostrada.

Este entero desarrollo, que comienza (para sí) con la filosofía positiva, es un modo eminentemente especulativo. Se trata de un área en el que no cabe un mero pensamiento mecánico de tipo erudito, como pueda ser la posición de un simple maestro común de cálculo en la especulación del análisis de lo infinito, quien, en su ignorancia, dicho trabajo debe parecerle una simple arbitrariedad. Son por tanto posibles y admisibles distintas presentaciones, dado que en el más elevado análisis se puede llegar por diferentes caminos a un mismo resultado, y también cuando un resultado es ampliamente demostrado, se busca incluso el paso más sencillo, lógico y claro de esta demostración.

La razón, al final de la filosofía negativa, está puesta fuera de sí, está de alguna manera afectada, porque ve que en esta filosofía no puede poseer su verdadero contenido como algo efectivo, y se decide partir por el ser de todo pensamiento. Ella se supedita a este pensamiento, pero sólo para alzarse inmediatamente de nuevo contra el mismo con la señalada pregunta de qué (Was) es el ser imprepensable. Así esta pregunta tiene en el ser imprepensable de un modo inicial e inmediato sólo el existir imprepensable mismo, de tal modo que nadie puede sustraerse de la conclusión que reza, como en Kant, lo que sigue: "si algo existe (lo hipotético de la expresión indica que el presupuesto es aquí lo que igualmente puede tanto ser como no ser, el mero ser contingente por tanto) debe así existir también alguna Unidad (y lo que ello sea queda indeterminado) de una manera necesaria». Si desde el comienzo no sabemos nada del Existente necesario, del modo como se eleva su existir necesario y sobre la pregunta en definitiva por el qué, lo que debe ser preguntado es simplemente si el ente imprepensable es sólo el $a c t u$, o bien si su naturaleza es conforme al Existente necesario (o más breve en lugar de lo último: si el existente necesario mismo es). Esto es así si el actu Existente necesario, el Existente necesario mismo del cual partimos, no fuera comprendido a priori. Así pues, este Existente necesario actu no tiene ya en sí mismo ningún prius por el que podamos acceder a aquél. Es, como hemos aceptado y presupuesto, el absoluto prius, y lo que nosotros podemos reconocer de nuevo de él puede ser sólo un mero reconocimiento a posteriori. Conforme a ello, por tanto, nos ocuparemos de nuevo de la labor que se nos ofrece en la proposición disyuntiva: o el Existente necesario actu es meramente así, o el Existente necesario mismo constituye el segundo miembro de esta sentencia que aceptamos como hipótesis para concluir que cuando éste se muestra como verdadero; esto es, cuando en aquel Existente necesario actu lo que aparece es el Existente 
necesario mismo (cuando en el necesario Existens es la natura necessaria), entonces debe encontrarse lo que se sigue de ahí. Hemos desarrollado también inicialmente la premisa mayor en su forma general. La proposición subsiguiente puede ahora encontrar el ser, un todo que hemos demostrado como consecuencia de aquella hipótesis, que se encuentra como lo efectivo, con lo que entonces aquella hipótesis concluye por ser tal. (Esto nos conduce a la rectificación de la carencia, pues efectivamente sólo hacemos pasar al ente (Seyenden) imprepensable, inmóvil para sí, por medio de la ayuda de una hipótesis. Porque en este desarrollo hemos oído formulada la palabra hipótesis de tal manera que de su conclusión se extrae lo siguiente: que todo ha de residir en la forma de la hipótesis. Luego en una ciencia rigurosa debería estar prohibida en general la conclusión hipotética, de la cual tenemos necesidad sin embargo en una multitud de casos, como cuando las matemáticas se sirven propiamente en la demostración apagógica). Según esta aclaración del "si" (Wenn) de nuestra premisa obtengo la siguiente consecuencia inmediata: La naturaleza propia del Existente necesario debe ser, como mero existir necesario actu, lo indiferente, algo en apariencia contingente en sí mismo. Por tanto, no ha puesto su querer en este ser (este ser imprepensable lo es sin su querer). Tiene también por ello frente a este ser un hacer libre. Es por tanto lo que permanece libre, así como también lo que está en disposición de poder algo, naturalmente sólo el otro ser en disposición de poder algo. Otro ser como ése es aquel ser imprepensable. La natura sua debe trascender, sobrepasar el mero actu Existente necesario. Como tal, debe ser más que todo ello. Sin embargo, en este "Más" (Mehr) no puede ser nuevamente el ente (Das Seyende). Entonces dicho ente está así ya dado por anticipado, de manera que alcanzará a ser el poder-ser, y verdaderamente lo que por encima de sí, por encima de ser el ser imprepensable, sería el poder-ser. No será sólo potentia actus (Potencia de un Actus), pues éste (actus) es efectivamente a priori, por tanto, sólo potentia potentiae. Éste queda ahora ya por fin suficientemente claro. Sólo cuando a su vez el Existente necesario mismo es en el verdadero ente infinito, entonces este Existente necesario no será por ello todavía tal. No se sabrá (wissen) todavía por tanto como el actus originario instalado por encima del poder-ser. Esto debe ser particularmente mostrado todavía (es decir, saberse como lo que está sobre el actus imprepensable que sobrevuela el poder-ser). Luego es hasta ahora lo que sólo en y para sí; es decir, lo que sin su naturaleza para el querer y el saber, está en cambio ya en movimiento, sin retorno sobre sí mismo. Tiene aquí en cualquier caso la necesidad de un pensamiento completo. El existir imprepensable está ya anticipado en todo concepto. No está determinado a través del concepto en la medida en que verdaderamente es un existir necesario, pero en cambio es sólo únicamente un necesario-contingente; o sea, un existir ciego. Como

Thémata. Revista de Filosofía №58 (2018) pp.: 35-48. 
tal no excluye al ser opuesto (lo puesto a través de la transición a potentia ad actum). Por lo demás había debido partir del concepto mismo. Verdaderamente éste no tiene ahora en absoluto ninguna exigencia sobre la realidad efectiva a través del proceso a potentia ad actum del ser posible. Este discurso no podría ser en modo alguno algo efectivo si no se tratara del ser imprepensable. Este ser sin embargo es, y es incluso verdaderamente de un modo ciego; es decir, contingente, un mero ser contingente que tiene también frente al ente (seyenden) un derecho a aparecer como una posibilidad, mostrarse, constituirse en el existir necesario actu como auténtica mismidad, como la esencia. Preciso de estas expresiones porque esta posibilidad es para sí una mera apariencia, algo que está en frente de algo que se muestra, algo que formula meramente que ello mismo es el poder-ser, lo que se libera justamente de la condición del existir inmediato que se coloca fuera del poder-ser, lo que puede elevarse sobre este existir que adopta una posición objetual (gegenständlich). Por tanto lo que hasta ahora era el ser mismo en la posición del sujeto. Junto al poder-ser, como aquello que se ve, hay ya un punto de partida fuera del ser, un пой, a partir del que se mueve en su ser fuera de sí. Éste puede igualmente alzarse fuera de su estado, no para anularlo absolutamente, sino para ponerlo en una condición de negación, tal como ha sido ya aclarado.

Nosotros distinguimos el Existente necesario actu de lo que es el Existente necesario mismo. Éste es por ahora una mera idea, aquello que presuponemos en el ser imprepensable, pero cuando aquél se encuentra en éste (esta es justamente nuestra hipótesis), debe también ser elevado en su idea a través de la aparición de la potencia opuesta. Es decir, debe verse a sí mismo como lo que no es más simplemente el existir, sino la naturaleza para el existente necesario. Y éste es auténticamente Dios. Pues Dios es, como se ha discutido ya, no lo simplemente necesario, sino la necesaria esencia necesaria, la natura necessaria, lo que, para serlo, no precisa del existir mismo. Es lo que permanece el ente (Seyende) necesario, también incluso cuando el ser necesario o el existir es superado. Este quod inicial non per existentiam existit; es decir, quos existit, sed non per existentiam existit. Es lo que en primer lugar llamamos Dios. Ello vale aquí para el concepto del simple y verdadero ente necesario actu, del cual, por cierto, no puede deshacerse particularmente Spinoza, hasta acceder al concepto del ente necesario natura sua. La dialéctica consiste aquí en reconocer en el existir necesario actu lo contingente. Cuando en el mero ente necesario actu está el ente necesario mismo, debe presentarse de este modo en éste aquel ser, aquel actu como un ser contingente y, por tanto como un ser superado, no como un ser inmediato y suprimible a través de sí mismo esto sería imposible -, sino probablemente como suprimible a través de un ser postrero (nachkömmendes Seyn), a través de un ser fuera de él, que po-

Thémata. Revista de Filosofía Nº58 (2018) pp.: 35-48. 
drá mostrarse como posibilidad. A través del fenómeno de la potencia otro ser aparece previamente a aquél mero existir necesario actu mismo como contingente, suprimible, y no como el ser que puede algo (Können). Pero precisamente con ello se desembaraza el Existente de su existir y aparece en ese su existir como independiente con respecto de esta necesidad. En el fundamento podíamos querer (Wollen) desde el comienzo ciertamente sólo aquello cuya naturaleza misma se dirige hacia la necesidad. Lo que se presenta inmediatamente y a primera vista, el ente necesario actu, lo hemos puesto tan sólo porque no podemos hacerlo de otro modo. Igualmente por tanto también sólo a ciegas. Es la razón ciega (blinde), que no se pone como el ser necesario actu. Lo que habíamos denominado el ente imprepensable, era, como se muestra ahora, también sólo el actus del actus purus, el cual como actus era sólo contingente, lo imprescindible, pero ante el que no se vería precisamente por ello el actus purus mismo. Sin embargo, sólo en cuanto es suspendido el actus del actus purus, queda atrás el actus purus mismo como esencia, y es puesto como esencia. El verdadero concepto de Dios no es otro precisamente que el del actus purus; es decir, el ser actus purus como esencia.

Que nosotros extraigamos primero del actus purus mismo su actus, el cual queda entonces apartado, es algo inevitable en este desarrollo. Es lo que podría reprochársenos por parte de los que colocan atributos negativos en Dios. Es decir, aquellos para los que Dios no es todavía tal, y para los que Dios no posee su divinidad. Naturalmente sólo debería expresarse así lo eterno, lo que del ente mismo (quod a se est) puede ser Dios (y se querría por ello llamar a este atributo también el atributo a priori de la divinidad): sólo lo eterno puede ser Dios. Pero Dios no es entonces lo necesario: Dios es sólo a posteriori. No es el paso necesario de los atributos negativos de Dios a los positivos (bajo los que Providencia, Sabiduría, Bien y el resto le pertenecen, y por medio de los cuales Dios es auténticamente Dios), proceso que la teología no ha encontrado hasta ahora. Los atributos negativos solo para sí conducen al panteísmo; los positivos inicialmente al concepto de lo que podemos llamar el verdadero Dios. Sin la presuposición de lo imprepensable; es decir, lo necesario-contingente de la explicación anterior, el ser ciego (blinde) en este sentido, Dios no podría ser en absoluto Dios. Y es que no podría ser lo que está por encima del ente, no podría ser el Señor del Ser, tampoco por tanto el Señor a secas, como deberíamos querer de él cuando le queremos solamente en general. Sin embargo, la divinidad de este ente (Seyenden) a priori se deja demostrar efectivamente sólo a posteriori. Entretanto aquel ser dado enteramente en Dios es ante sí mismo y sin su intervención tal ser, pues Él lo tiene con antelación en y para sí mismo, y sin lo que Dios no podría ser Dios. Este ser es tan sólo un pensamiento del instante, por el que también ha pasado. Es sólo una presuposición de la

Thémata. Revista de Filosofía Nº58 (2018) pp.: 35-48. 
cosa, ajena al tiempo en este caso. Así como también el existir es en aquel ser imprepensable, conoce por tanto también desde la eternidad no tener necesidad de este actus del existir necesario. Él, el existir, sabe que está sobre el existir fuera del existente necesario, y su divinidad estriba precisamente en ello.

Desde la eternidad se ve por tanto, como Señor, anular su ser imprepensable. Naturalmente no superarlo de un modo absoluto, sino suspenderlo para poder establecerlo por sí mismo ayudado de un proceso necesario y para, queriéndolo libremente, devenir así su ser divino necesario. Él, digo, se ve conferido en tanto que Señor para hacer esto. Pero preguntamos ahora, ¿por qué debería hacerlo? Hasta ahora permanece todo únicamente en el interior de la posibilidad, pero, ¿cómo puede Dios ser sólo lo que ha podido ejecutar lo que se le presenta como posibilidad, haber anulado el ser imprepensable y poner en la posición de este ser inconceptualizable un ser comprensible, haciendo efectivo lo que se le presenta como posibilidad? Una dialéctica inmóvil junto a otra, más la ya mencionada, podría ser suficiente para decir que Dios toma la potencia del ser opuesto, a través de la cual sienta su existir imprepensable ex actu en el ser. Queda así establecido en el curso de las potencias para transformar en el ser establecido lo que no tiene como opuesto, en el ser querido mismo, y transformar así la repentina y ciega afirmación de su ser a través de una negación mediada. ¿Pero para quién debería hacer tal cosa? ¿Para sí mismo? Imposible. Así pues, Él sabe con antelación que aquel ser necesario en acto es reconstituido, certificado como tal. Sobre sí mismo tampoco habría querido establecer la tensión de la negación del ser imprepensable. Expresándonos de un modo preciso debemos decir que si Dios pudiera simplemente provocar todo esto en torno a su propia voluntad, ello no podría hacerlo indiscutiblemente. ¿Para qué debería servirle un proceso que para Él mismo no tendría ningún objetivo? También puede decidirse por este proceso sólo a causa de algo fuera de sí, praeter se ("fuera de» es = praeter y extra, a partir del segundo término. Pero este no es el tema del actual discurso). Él puede sólo decidirse por la suspensión de su eterno ser actu a causa de algo al margen de sí, no movido por tanto por algo que estuviera fuera de Él, sino a causa de algo que fuera ya a través de este proceso efectivo, y cuya posibilidad ve mediada justo a través de la potencia auto descriptiva que es inmediata para Él. Como Señor, engendrar uno de sus diversos seres es algo que se encuentra enteramente en el camino hacia sí mismo. En este poder-ser en pos de sí consiste sin embargo para Dios tanto su libertad absoluta como su absoluta Bienaventuranza. Esta afirmación podría llamar la atención de quienes sólo contemplan como lo único que puede conocerse de Dios aquel último concepto de la filosofía negativa, según el que Él sólo podría ser lo eterno, el Sujeto-Objeto sempiterno, o, como Aristóteles 


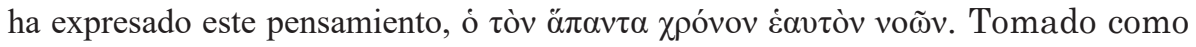
mera determinación conceptual, nada se adelantaría finalmente con esta expresión aristotélica que enuncia a Dios como esencia sempiterna para el ente-para-sí (bei-sich), consciente de sí mismo. Aristóteles ha querido describir evidentemente con ello simplemente el concepto, la esencia de Dios, poniendo en este sentido todo el esfuerzo en describir aquel permanente ser-para-sí (bei-sich) como la dicha misma, como un estado en definitiva eterno. Por tanto, el deleite más elevado, dice él, está por doquier en actus, por ejemplo, durante la vigilia, en el pensamiento, siendo en la sensación mayor la alegría que en el sueño, tanto como en la ausencia de pensamiento, la ausencia de sentimiento, etc. La esencia más elevada no es sin embargo la mera potencia del pensamiento, tal como actúa en nosotros la mera potencia del pensamiento. Lo regular desaparece en el sueño, y para algunos lo habitual también queda dormido bastante a menudo fuera del tiempo, para un tiempo, en definitiva, completamente injusto. Dios es más bien el actus sempiterno del pensamiento, y ahí Él no puede pensar otra cosa más que lo más divino de todo, de modo que será sin cesar sólo el pensamiento en sí mismo. Como queda dicho, ello sólo puede hacerse valer cuando el discurso versa en torno al mero concepto; es decir, en torno a la mera naturaleza de Dios. Pero cuando justamente también debe consistir en la actividad del Dios efectivo, debemos ver en el pensamiento de una permanencia el límite más embarazoso de todos. Nada puede ciertamente ser más engorroso que pensarse sólo a uno mismo, pensar en sí mismo sin cesar. El hombre exige salir más bien de sí, así como también quedar pegado a sí mismo, igual que aquellos hombres, verdaderamente no lejos de los más afortunados, que por lo general se organizan al margen del resto, y que hace de ellos algo intelectualmente independiente, algo objetivo. Johannes Müller escribe en una de sus cartas: «Tan sólo cuando produzco soy afortunado». Esto concuerda con todo lo que no es azotado con algo así como una improductividad intelectual. En el producir en cambio no está el hombre consigo mismo, sino que está ocupado con algo externo. Justo por ello Dios es el gran bienaventurado, como le denomina Píndaro, porque frente a todo lo exterior, frente a su creación, todos sus pensamientos son sempiternos. Él sólo tiene que ver consigo mismo, es a priori su ser seguro y cierto. Sin embargo, el proceso por el que Dios se ve mediado a través de las potencias que se le presentan no deja de ser el proceso de una suspensión, con la que queda mediado y asentado el restablecimiento de su ser necesario. Y entre aquella anulación y este restablecimiento yace el mundo entero. El ser imprepensable se desfondará sólo para dar espacio a la creación (por eso, porque algo está desfondado, surge con ello la creación, siendo el espacio la forma a priori de todo ser finito). El mundo no es en absoluto otra cosa que el actus suspendido del necesario existir divino, la

Thémata. Revista de Filosofía №58 (2018) pp.: 35-48. 
esencia suspendida. Por tanto, éste es lo inabrogable, aquello a través de lo cual la supresión del actus quedará únicamente elevado en sí mismo.

Dios no se aliena al conducirse al mundo, como se acostumbra ahora a decir. Él se eleva más bien en sí mismo, en su divinidad. Él es creador, y con ello pone un pie en su divinidad. Él está más bien alienado en el existir ciego, imprepensable. En tanto se aliena respecto de esto último, este existir se pone fuera de sí (así como en frente de sí), y con ello Él se dirige hacia sí mismo. Se dirige hacia su concepto, del que estaba fuera hasta ahora - justamente en el ser imprepensable -. Al mismo tiempo, empero, Dios suspende sin embargo el actus de su existir necesario, no sólo para afirmarse nuevamente, sino para establecer un ser distinto a partir de su posición. Para hablar en general, Dios tiene en aquel mero poder-ser lo que se le presenta desde la eternidad, lo que sencillamente es algo en la medida en la que Él lo quiere, y que no es nada en tanto que Él no lo quiere. Dios tiene en este poder-ser como real, no sin más lo pensado, el principio de la misma indiferencia, el mismo ser y no poder-ser, que en la filosofía lógica hemos determinado como materia prima de todo pensamiento y de todo lo pensable. En ser y no poder-ser simultáneamente tiene Dios el fundamento real del que todo viene a la luz, y desde el que puede generar todos aquellos momentos como efectividades que en la filosofía negativa se daban meramente como posibilidades. Lo que en la filosofía negativa era un simple paradigma, aquí es lo efectivo. Las mismas potencias que se nos presentan en la filosofía negativa como a priori, y mediaban para nosotros todo lo concreto, se presenta aquí de nuevo (en la positiva), pero no como simples potencias. Es decir, no como las que parten del ser, sino como las que tienen el ser para su presuposición, y ello como esencia del ser postulado y por ello también para su unidad indisoluble. Aquello que vincula a estas potencias es justo lo que para la esencia es el elevado actus purus, que tampoco es como unidad suprasubstancial superable a través de nada que sea substancial. Las potencias presentan el mero existir material. El purus actus como esencia está por encima de la mera materia del ser. Es por tanto lo supramaterial, justo por ello la unidad indisoluble e insuperable, cuyas potencias no establece por separado. Las potencias son de algún modo lo originado, el ser originado ex improviso y el ser originario negado de él - por tanto en una tensión puesta en pie con él -. Las potencias lo fuerzan a ser uno eodemque, siendo también la unidad lo que preside las causas materiales de todo proceso cuya razón es supramaterial. La unidad indisoluble llega por tanto a afirmarse para la causa de un proceso en general. Podríamos pensar de antemano lo generado como si deviniese el conjunto de las posibilidades a priori de toda efectividad concebible, que

Thémata. Revista de Filosofía Nº58 (2018) pp.: 35-48. 
llegaran a ser un по̃v, un Todo, el ser del mundo, el cual es a la par algo tanto lógico como real, y al mismo tiempo algo tanto real como lógico.

Sin embargo, el punto en el que se vincula la perspectiva planteada y Dios como este posible proceso, descansa tan sólo en aquél ser no presenciado anteriormente y descubierto ex improviso como posible, cuya naturaleza puede aparecer sólo para lo contingente, pero en cuyo aparecer encuentra ante sí el ser imprepensable como lo que existe (Daseyn) y ha sido ya siempre (aquí la palabra existencia (Daseyn) se encuentra en su significado auténtico). Pero también Dios se convierte previamente en su ser no sólo a través de aquella posibilidad por encima del ser imprepensable, ahora fuera del poder-ser (Hinausseynkönnende), sino también a la par en su ser imprepensable interior, de modo que Él se ve en el medio entre ambos como un tercero, libre de ambos. A través del poder-ser libre del Ser, este tercero es auto-potencia, auto-poder, en la medida en que es puro sujeto. A través del ser libre del poder está en este sentido frente al poder ser-mismo, el objeto-mismo. Por tanto, está en uno y el mismo sujeto y objeto, es, por tanto, el inseparable sujeto-objeto en general, la objetualidad inseparable en sí misma. La posesión en sí mismo, lo que permanece necesariamente para-sí, lo que no puede ser únicamente sujeto ni objeto, lo que debe ser sujeto y objeto, y que es por tanto espíritu. Estos son los tres momentos a partir de los cuales el prototipo de toda existencia (Existenz) se junta inmediatamente en la intuición divina o en el propósito divino, del mismo modo como Él quedaba fundamentado en la filosofía negativa. Así, el comienzo de todo existente, el comienzo de todo existente en sí mismo, es el mero sujeto para el ser, todo ello en la medida en que no está siendo aún aquello que puede ser. Esto es, el mero sujeto para el ser, aunque sin ser todavía, y pensarlo por tanto como mera potencia, como mero poder. Este es el comienzo interno de todo existir, el in-icio porque a través de su no-ser infinito es justo la potencia atrayente del ser de este modo infinito, y que es por ello lo segundo y sólo lo segundo. Comienzo y retracción son entonces palabras para conceptos equivalentes. En la retracción subyace el comienzo. Aquella potentia ultima es la potencia retractiva del ser a través de su negatividad infinita de un modo justamente infinito, y es por ello lo segundo y, juntamente con ellos, el ente, pero el ente todavía separable, mientras que el sujeto del ser puede dar la espalda a este ser, y llegar a ser un ente (Seyendes) para sí. Su determinación según la objeción hecha al ser infinito, al sujeto, el poder intransitivo hasta este punto, puede bien volverse igualmente hacia fuera como potencia transitiva y transformarse incluso en el ser, donde igualmente actúa aislada y retraídamente sobre el ser infinito como antes lo había hecho de un modo atrayente y aferrado. Pero justo porque el ente, el cual en efecto está puesto ya con el sujeto puro como lo atrayente, y el objeto como lo atraído (pues este ente es divisible)

Thémata. Revista de Filosofía ํ58 (2018) pp.: 35-48. 
es ya el ente consumado junto con el tercero, el cual es el Uno y el Mismo sujeto y objeto; esto es, el inseparable sujeto-objeto. Con el primero está ya puesto el ente consumado, sin que pueda decirse con ello que éste sea para sí lo consumado o el Absoluto. No puede ser tal cosa porque verdaderamente no puede ser sólo para sí, porque verdaderamente sólo es posible como tercero. Fuera por tanto de lo que se le presenta, fuera del poder-ser inmediato, fuera del ser imprepensable y lo que, por encima de ambos, es libre de uno y otro, Dios se compone de aquel prototipo de toda existencia (Existenz) del que resulta todo el existir efectivo. Pero Él no tiene en sí todavía este arquetipo (Urbild) como algo realizable. Para realizarlo, Él debe salirse del poder-ser, llegar a ser él mismo lo que existe, quedando así superado el ser imprepensable. Es decir, alzarlo a lo más elevado, levantarlo por tanto hasta la potencia. Inevitablemente con ello llega ahora también a ser lo tercero, el sujeto-objeto inseparable, excluido y negado. Entretanto el tercer elemento en absoluto se conduce con ello separadamente de todo existir, pues Dios es justamente en ellos el Uno insuperable, así como están también sin embargo ligados en la tensión mutua y en la exclusión. Pero con ello se encuentra en ellos la contradicción, poniéndose con esta contradicción un proceso necesario a través del cual lo que debe ser el sujeto puro, y lo que porta como tal la entera unidad, es superado de nuevo en el sujeto, en el puro poder. Es así como aquel arquetipo del existente, que Dios solo puede querer de un modo finaliter, llega a realizarse. Pero entre el arquetipo materializado y la tensión primera puesta a través de la voluntad divina, yacen todos los momentos del proceso que habíamos previsto sólo como posibles en la filosofía negativa. Éstos retornarán aquí de nuevo como momentos de un proceso ahora necesario.

\section{Glosario}

aufsthende Seynkönnen: ser-supra-posible

ausgeschlossen: anulado, exclusivo

bei-sich: para sí, cabe sí

blind: ciego, falso

Daseyn: existencia

Das Seyende: ente

Existenz: existencia

gegenständlich: objetual

Hinausseynkönnende: poder ser hacia fuera

Können: poder

mehr: más

die Monas: la Monas

nachkömmendes Seyn: ser postrero

Thémata. Revista de Filosofía Nº58 (2018) pp.: 35-48. 
Obersatz: premisa mayor

ohne: sin

Seynkönnende: poder ser

unvordenkliche: imprepensable, inmemorial

Urbild: arquetipo

Was: qué

wenn: cuando

wissen: saber

Wollen: querer

Traducción de Miguel Ángel Ramírez Cordón ${ }^{1}$

Universidad Complutense de Madrid

1. (miguelramirezcordon@gmail.com) Licenciado en Historia (Universidad Complutense de Madrid). Licenciado en Teoría de la Literatura y Literatura Comparada (Universidad Complutense de Madrid). Licenciado en Antropología Social y Cultural (U.N.E.D.). Doctor en Filosofía por la Universidad Complutense de Madrid.

Thémata. Revista de Filosofía $\mathrm{N}^{\circ} 58$ (2018) pp.: 35-48. 


\section{RESEÑAS}


